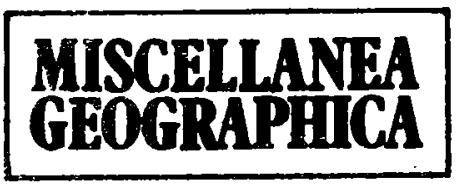

WA.RSZAWA 1990

Jadwiga Winid

\title{
SOME NOTES ON POPULATION MIGRATION IN BANGLADESH
}

Many contemporary authors writing on migration in Asia have noticed that in Muslim countries there is a predominance of temporary economic migration over the permanent one and that this phenomenon concerns mainly men (T. Fawcett Ean Khoo. S., P.C. Smith, 1984). The basic difficulty in the analysis of migratory movements in that part of the world is lack of statistics. Research on internal migration in Bangladesh is fragmentary. It has been conducted by M. Obaidullah (1967), J. Stoeckel, A.K.M. Alaudin Chowdhury and K.M.A. Aziz (1972), R.H. Chaudhury and G.C. Curlin (1975) and P. Krishnan and G. Rowe (1978).

VLS Prokasa Rao (1983) belongs to the authors who have been emphasising the tremondous social and cultural gap between urban and rural area. They hold that this gap is due to modern development processes and has been steadily increasing. Other authors maintain that towns are in fact agglomerations of villages since their inhabitants resemble villagers in their outlook, mentality, life style. In case of Bangladesh this cultural continuity between town and colntry is very clear and the process of migration is the process of town ruralization. Immigrants adapt very easily to new envinonments, which is due to the fact that towns of Bangladesh have the character of "rural agglomerations".

"Push" and "pull" factors influence the numbers of rigrants from rural to urban areas. 'They only relate to different social classes. In view of uncontrolled migration in Bangladesh, the areas that receive migrants are, first of all, the biggest towns, which is the reason why the growth rate in towns is very high. At present it is this phenomenon that is the most decisive in the shaping of the country's urbanization. Directing immigrants to medium-sized or smaller towns or even establishing new places for immigration might be of some help. However, all actions undertaken in this sphere have been, so far, insignificant.

Due to lack of statistics on the scope of migration in Bangladesh, the author of this paper has used hypothetical assumptions for the marking of emigration and immigration areas. 
According to Bangladesh population censuses of 1974 and 1981, for one woman there were 1.079 and 1.064 men, respectively; in the same years in towns the men-women ratio was 1.294 and 1.258 , respectively. In urban areas the coefficient of birth and the average life duration of men do not diverge from the national figures. Thus, it is possible to develop a hypothesis that the $20 \%$ surplus of men in towns results from greater influx of men to these areas.

In $1981,51.5 \%$ of total population were men, while in towns they constituted $57,2 \%$. Thus, the question arises whether areas with a lesser percentage of male inhabitants - 51.5\% - in relation to the entire population are the ones affected by emigration to towns and those above - 51.5\% - are the areas of immigration? A full answer requires thorough field work; however, due to the absence of other data, the above-mentioned hypothesis has been used as the basis for the analysis of 71 administrative units in Bangladesh - the so-called subdivisions.

The method used for the purpose of this analysis provides merely approximate data. Therefore, the results should be considered as only probable and informative as to the scope of the issue.

The analysis was based on the 1981 Bangladesh population census. Ten variables ${ }^{1}$ were used as the basis for calculation; in the course of the analysis they were compared with average national values. The results allow for a classification of subdivisions as regards the surplus or shortage of men in relation to the national average. In this way, according to the original hypothesis of the paper, a spatial view of emigration and immigration areas was established (Map 1)2.

The following subdivisions have the highest number of immigrants, in successive order: Kaptai, Dhaka, Lama, Chittagong, Rangamati, Khulna, Bandarban, Khagrachari, Ramgarh, Barisal.

As has been mentioned above, towns receive most of the immigrants.

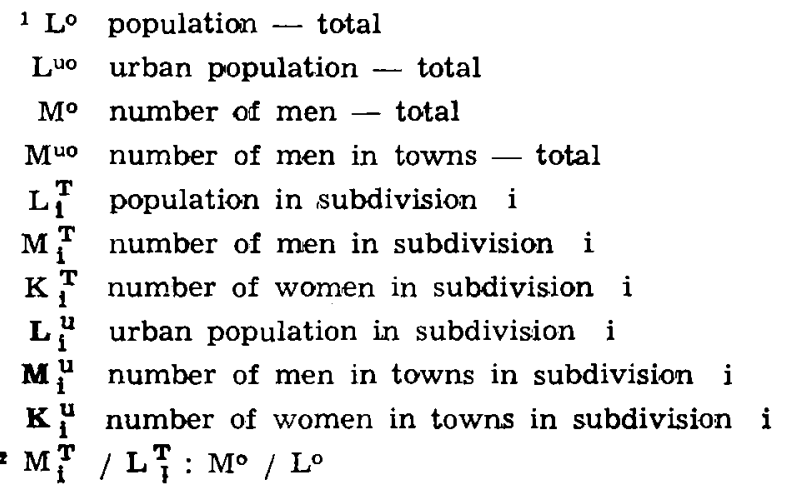





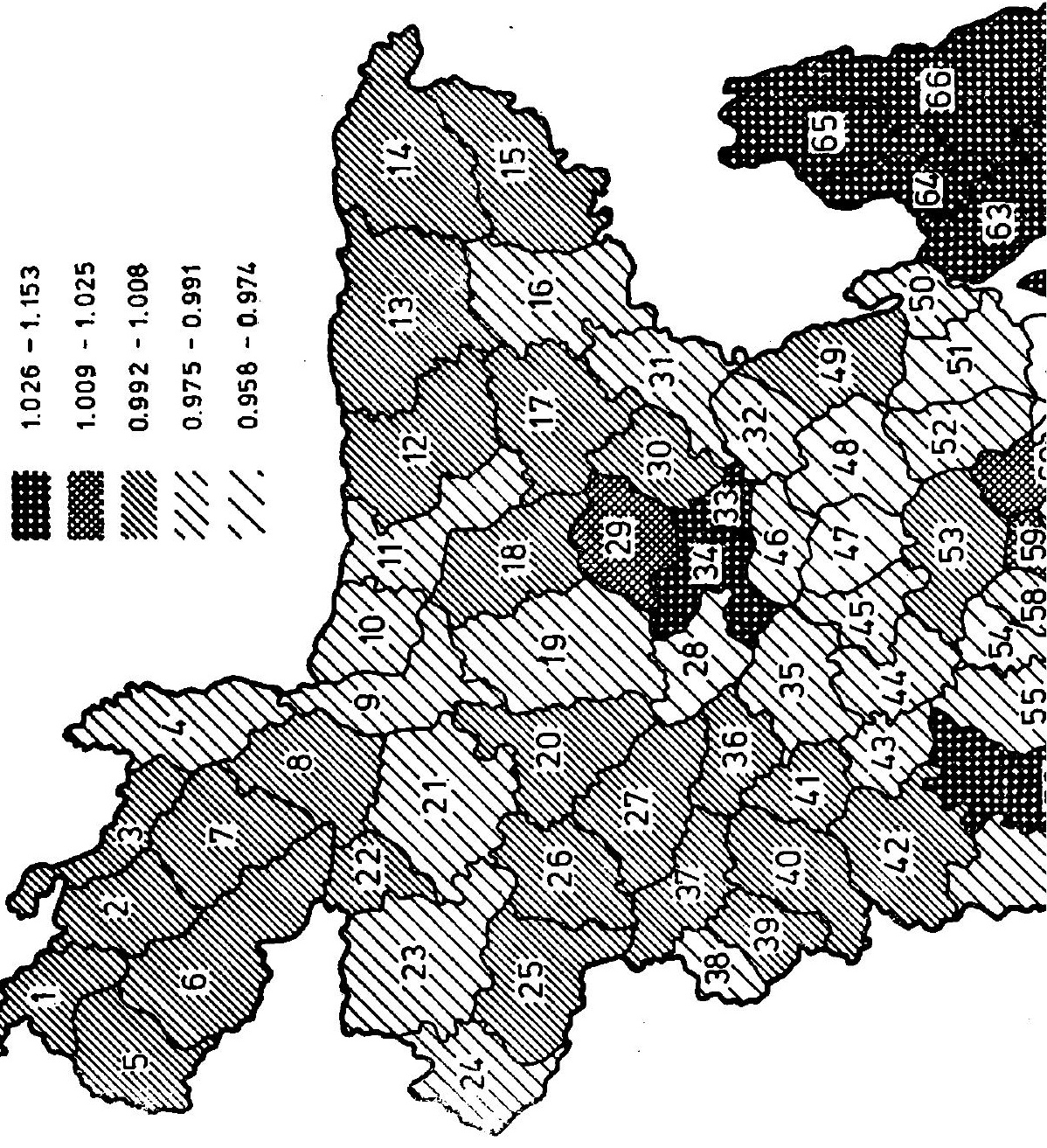




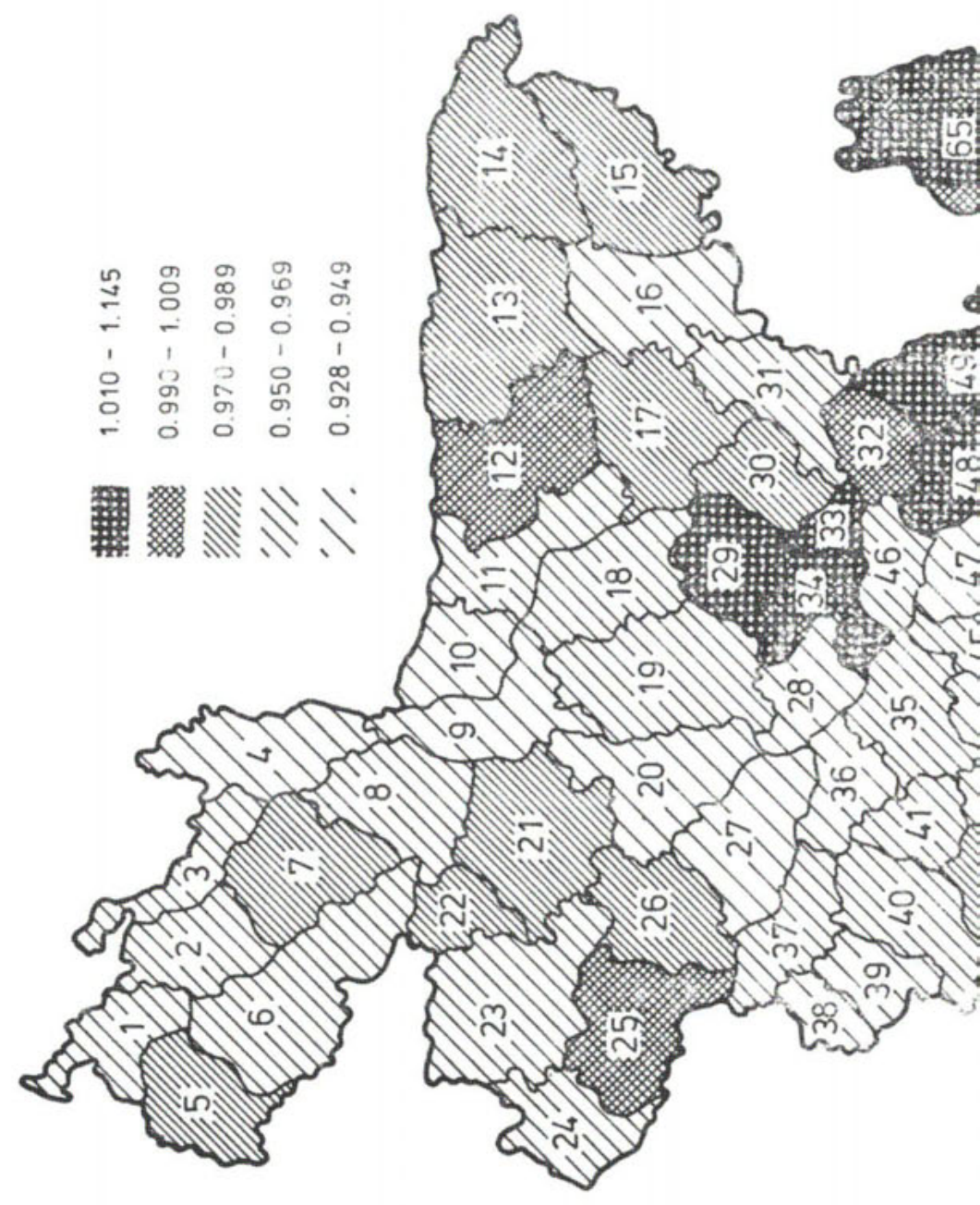



This has inclined the author of this paper to conduct similar calculations with reference to the number of men living in towns in relation to the entire urban population of the analyzed subdivisions and subsequently to compare the obtained data with the value of the national index (Map 2) ${ }^{3}$.

It has to be pointed out that the indices reach the highest value in the following subdivisions: Gazipur, Chittagong, Kaptai, Dhaka, Narayanganj, Jhalakati, Rangamazi, Bandarban, Khagrachari, Feni and Chandpur.

From the economic point of view Dhaka, Chittagong and Narayanganj occupy a special position in Bangladesh, which encourages immigration. Also a greater number of men live in other urban areas of Feni, Chandpur and Jhalakati subdivisions, since these places are the regional centres of bigger development.

The extremely high index of masculinization in Chittagong Hill Tracts subdivisions of Kaptai, Rangamati, Khagrachari and Bandarban is difficult to account for. It is hard to answer unequivocally whether this considerable predominance of men reflects the changes in the economic development of towns, or the presence of military units which are covered by the population census, or merely the inaccuracies in statistical data. One has to add that - especially in recent years - towns like Kaptai or Rangamati have been undergoing developmental changes. Other towns, however, are among the most neglected urban areas in the entire country. An answer to this problem requires a detailed analysis.

The above observations provide merely approximate data. However, they provide enough information for establishing a classification of subdivisions as areas of emigration or immigration in accordance with the assumed hypothesis.

It is difficult to assess the precision of demographic statistics of Bangladesh, especially the south-east part of the country. The data used for the analysis point only to tendencies within the examined phenomenon.

If our hypothesis referring to the value of the masculinization index is correct, then the areas of present-day immigration, especially such subdivisions as Dhaka, Chittagong, Narayanganj, Feni, Chandpur, Barisal should preserve their power of attraction. Continuing state and private investment in these areas will create further employment opportunities and, as a consequence, will increase migratory movements. Although it is based on general material, the statistical classification

${ }^{3} M_{1}^{u} / L_{1}^{u}: M^{\text {uo }} / L^{u o}$ 
presented here reveals the influence of economic factors on demographic phenomena.

Moreover, this analysis leads to further conclusions. Contrary to popular belief, the "pull" factors (factors that draw people to towns) are not the "attractions" of urban life or its more luxurious life styie. Migratory movements in Bangladesh have to be regarded as employment oriented. Financial and economic opportunities are the basic factor behind the emigration from village to town. This fact confirms the disastrous economic situation of the country which has been deteriorating due to increasing financial difficulties. Its effects are to be seen in a steadily growing number of the unemployed or only temporarily employed in towns. Therefore intensification of agriculture as well as gradual change in the system of employment in rural areas have become the key economic problems of Bangladesh. The necessity to counteract the increasing migration into towns, especially large ones is strictly related to modernization of rural areas, the development of home industry (crafts), location of industrial plants processing local raw materials in rural areas, intensification of agriculture-especially "small-goods" agriculture, growth of trade and services as well as improvement of supply of indispensible articles of everyday use. Any' actions undertaken in this direction provide perspectives for the advancement of the rural areas and, consequently, may slow down migration. to towns. They should become the object of special care of the state authorities as well as should find an appropriate place in economic plans and programmes of international organizations.

\section{REFERENCES}

Bangladesh Bureau of Statistics, Bangladesh Population Census 1981, Analytical Findings and National Tables, 1984, Dhaka.

Chowdhury, R.H., Curlin, G.C., 1975, "Dynamics of Migration in a Rural Area of Bangladesh", Bangladesh Development Studies, vol. III, No. 2.

Fawcett, T., Ean Khoo, S., Smith, C.P., 1984, Women in the Cities of Asia, Westview Press, Boulder, Colorado.

Krishnan, P., Rowe, G., 1978, "Internal Migration in Bangladesh", Rural Demography $5 / 1$ and 2.

O baidul1ah, M., 1967, "Internal Migration in East Pakistan" Oriental Geographer, vol. 21, No. 2.

Prakasa Rao, VLS. 1983, Urbanization in India, New Delhi.

Stoeckel, J., Chowdhury, Aziz K.M.A., A laudĭn, A.K.M., 1972, "Migration from a Rural Area of Bangladesh", Rural Sociology, 37. 